\title{
Business Intelligence Systems in the business strategy - an approach to the Romanian reality
}

\author{
Serghie Dan, „Al. I. Cuza” University of Iasi, Romania \\ Balan Ana Maria, „Al. I. Cuza” University of Iasi, Romania
}

\begin{abstract}
The Economics doesn't mean an accumulation of disparate sciences, is a coherent set of related theories in the support of certain ideas from the schools of thought or arising from different research areas. In the Economics, the complementarities between practice and theory are potentiated first by utilitarian reasons and highlighted through the correlation between static systems with dynamic ones.

The dynamism of the market today, the volatility given by the competitive environment, the disappearance or weakening of the entry barriers in a sector of activity, make the information to become the most important asset of a company. The access to information, especially analysis, reporting and forecasting in real time (management information) represent the condition and the scaffolding in the competitive environment from our days.
\end{abstract}

\section{Key words}

Business Intelligence, information, system, data, decision.

\section{JEL Codes: M 15, M 16}

\section{The importance and the evolution of Business Intelligence concept}

The effectiveness in use of information is determined by an appropriate data structure, by its capacity of processing and synthesis, that provide to the manager from any level the data analysis necessary for operational, tacit and strategic decisions.

Together with the informational structure, an another tangible necessity in any organization is represented by the tools that are useful for watch and receive in a fast way the changes appeared in the external environment of the company, or in the social, legislative of administrative one.

On the segments related to the company's management spheres, the managers with different responsibilities will have access to information (collected, processed, analyzed and transformed into a form accessible and useful) corresponding to their targets:

- $\quad$ The sales management must always know which are the most requested products or services on market, which are the most profitable customers, what new products should be designed and offered, for being efficient and to compete;

- $\quad$ The financial management should always have in view the optimization (on the claim value) of the products or services and to improve the decision process for achieving performance and profitability criteria;

We could offer and another suggestive examples about a company's management structure, but we summarize to point out the most important results of using and processing information in real time, and this result is that with the help on information, is created the source that claim and generate innovation.

Within a company, the information system can have a rudimentary or a simplistic level (manual systems- information written on paper), can be also informal information systems 
(based on the transmission in the employment relationship, specific especially to the Asian companies) and automated information systems (based on hardware, software and human infrastructure). In conclusion, the collection, the processing and the dissemination of information is based on an organization system that includes: people, processes, material and financial resources, all of these being- more or less- ingredients of the system.

In 1989, Howard Dresner, researcher at the Gartner Group, propose the term Business Intelligence, defining it as "a set of concepts and methods to improve the decision making, using systems- support based on evidence"1. The IBM specialists consider Business Intelligence "using all the data available to a company to improve decision making ${ }^{2}$. Business Intelligence requires access to data, their analysis and the discovery of new opportunities in their use”. In an interview accorded in 2004, Shaku Atre defined Business Intelligence like "a developmental strategy, vision and architecture that keep a constant alignment between the operations/directions of a company and their strategic objectives"3.

According to the definition form Baets ${ }^{4}$, Business Intelligence represents "a store of knowledge in the business success". In his opinion, this "store" of knowledge can provide the business success in the adaptation to the environment transformations. The collection and the management of such knowledge is, in fact, the only sustainable competitive advantage.

The precursor researchers in Business Intelligence radically separate the field, to not be confused with a technology or a methodology. Business Intelligence is included in management and is boosted and made in value by the new knowledge economy.

The propose and the result of Business Intelligence application is found mainly in the efficiency of a performing decision process, through new knowledge. The classical approach or the start of researches was focused on waking information, on acquisition and storage of information, then putting them in a format accessible to managers.

Salles identifies four major periods concerning the evolution on Business Intelligence concept:

- The period of 1980-1990, when the concept is focused on processes, tools and techniques (Wilensky, Martre, Lesca);

- The early 90's, when the concept is defined primarily on he use of Business Intelligence like waking information and also is defined on its general objectives;

- Since the late 90's appear the concepts co-management and collective intelligence, organizational learning and working in collaboration;

- The early 2000's brought in addition to the earlier concepts, those of cultural identity, regionalism and the concept of "economic defense"

Business Intelligence is presenting as specific management information based on processes, tools, methodologies and tested skills.

So, like a system, Business Intelligence use data, processes, tools and technologies to obtain form the competitive, legislative, technological and innovative environment the useful information for decision- making.

A special feature for efficiency and profitability in organization is given by the global vision obtained form multiple perspectives.

1 Power, D. J. (2007), A Brief History of Decision Support Systems, available on-line at http://dssresources.com/history/dsshistory.html

${ }^{2}$ Muntean, M. (2004), Inițiere în tehnologia OLAP. Teorie şi practică, Ed. ASE, Bucharest

${ }^{3}$ Shaw, T. (2004), Shaku Atre Interview: What is Business Intelligence?, available on-line at www.dssresources.com

${ }^{4}$ Baets, W. R. J. (2005), Knowledge Management and Management Learning: Extending the Horizons of Knowledge- Based Management, Springer's Integrated Series in Information Systems, Vol. 9

${ }^{5}$ Salles, M. (2003), Stratégies des PME et intelligence économique: une method d'analyse du besoin, Ed. Economica, Paris 
A second key feature is given by the fast response to changes in the external environment of the organization.

\section{An approach in terms of information technology}

The researches that claim this approach have in view the following features of a Business Intelligence system:

- The quick access to data (information) stored in organization;

- $\quad$ Procedures for reporting and for effective data analysis;

- The ability to provide forecasts for future developments.

Thus, the basic concepts of this approach are transformed into Business Intelligence systems: the transformation data into information, the information into knowledge and knowledge into profitable business action.

In "Business Intelligence Roadmap" the concept is presented like an architecture and collection of applications and databases operational integrated, and also like a collection of decision support systems, providing to the business community an easier access to data.

Business Intelligence application to assist the decision facilitates many activities, including multidimensional analyses (eg. OLAP), data mining, forecasting ability, business analysis, facilities for query, reporting and making graphics, geospatial analysis, knowledge management etc.

Business Intelligence is an iterative process; it starts form the operational environment; the data are extracted form this medium and stored in data warehouses (the data warehouse is in form of a container data center, separate form operational data); the decision- maker use the decision support system to extract data from data store; holding this information, he can create action plans; this change in the operational information leads to a new iteration of Business Intelligence cycle ${ }^{7}$.

\section{An analysis of a Business Intelligence system in terms of Romanian realities}

\section{Coordination and dissemination of information}

Romanian executives are ambitious, eager to learn and work more, but we can not speak about them as a separate category, different from the cultural and business models of other countries.

One of the most common mistakes that are made by the managers from everywhere is the fact that they don't communicate enough. "The managers should put to themselves more questions on how they lead the companies and where "is going" the business, and than to communicate these things to the organization", says Bodo Schlegelmilch, WU Executive Academy dean of the University of Economics and Administration in Vienna.

It is vital for successful change at corporate level to know how to achieve coordination and information in complex organizations, geographically dispersed.

However, the managers are often tempted to not share the information or don't collaborate with their colleagues for coordinate the activities and achieve the strategic objectives in short-term. WHY? The answer to this question is vital for successful implementation of the strategy. If every manager would shape the piece of his business and would optimize and automate the processes such as he thinks is better, it is possible that the company as a whole, don't function better, but worse.

\footnotetext{
${ }^{6}$ Moss, L. T., Atre, S. (2003), Business Intelligence Roadmap: The Complete Project Lifecycle for Decision-Support Applications, Ed. Addison Wesley

${ }^{7}$ Giovinazzo, W., A. (2002), Internet - Enabled Business Intelligence, Prentice Hall PTR
} 
The most effective business modeling, it automates and optimizes, is when it starts from top to bottom, from the entire company's level and it uses a single system, or, anyway, a few systems, but being integrated as closely ${ }^{8}$. The automation at the level of departments or activities can become a disability if it can be integrated with the rest of the system, even if, in their piece, they do are very good job. Many times it better to give up to some "effect" features, but non-essential, for the sake of integration and for the benefits that it brings to the entire business. In other words, how a system can manage several departments or activities, the greater is the chances that, at the level of the organization, this system to bring more efficiency and the productivity to rise steadily ${ }^{9}$.

\section{Data classification}

Most employees have no clue (nor any interest) to classify the information and the documents. How many of those who read these lines doesn't take all the 2009 emails in their inbox and then use Advanced Search to search for something among the many thousands of messages? Even using the basic tools of taxonomy requires more intellectual resources than what is found normally in a company. One of the best reflexes rooted in employee behavior is to press the Print button. If he doesn't throw the paper as soon as it is read, then sure place it in a location where its presence there has no ninth. In time, the information doubles and triples go to overflowing... One of the major waste of resources of a company is by looking unclassified information (or poorly classified) and redundant information.

It is preferable that a business automation system company (management model + IT support) to be much smarter than most of its users. First, you must ensure that the system doesn't records information redundant, or vertically (over time) nor transverse (between departments). The information must be stored only once, in one place and must be retrieved at any time and by all departments that need it, using a uniform system of classification. The classification system must be sufficiently complex, must cover all types of data, completely adaptable to the type of work and the company's business model and sufficiently flexible so that adding new classes or classification criteria doesn't ruin the whole fabric already operational.

As a general rule, the system removes greater the use of paper in the current work, the redundancies can be reduced easily, the classification of information and documents is easier, and, obviously, and their retrieval is faster and more accurately. Finally, the risk of losing data is reduced to zero asymptotically ${ }^{10}$.

\section{The access to information resources}

There are few managers able to optimize their business department and always concerned with productivity. Of these, fewer are willing to share the results of efforts, information and contacts with others- being from the same department or from different departments- if they aren't forced by superior heads to do that. If that happens, obviously they will want and benefit from access to the resources of other departments.

The system should allow to those with the right to decide, through a complex of rights and permissions, to decide (and enforce!) that one's information can be used by someone else, under what conditions, if the access to information is or isn't symmetrical (the ones from the Legal department can see what are the information from the Procurement department, but not vice versa etc.). Basically, it's all for eliminating redundancies.

\footnotetext{
${ }^{8}$ Lesca, H., Caron, M. L. (1995), Veille stratégique: créer une intelligence collective au sein de l'entreprise, Revue francaise de Gestion, 105, pp. 58-68

${ }^{9}$ Lesca, H., Sadok, M. (2009), A Business Intelligence Model for SMEs Based on Tacit Knowledge, Communications of the IBIMA, volume 7, ISSN: 1943-7765

${ }^{10}$ Velicanu, M., Matei, G. (2007), Databases versus Data Warehouses, Communication at the 8th edition of the Conference of Economic Informatics, Ed. ASE Bucharest, published in the Conference volume
} 


\section{Indicators of business}

A key evidenced through practice is that the implementation of business strategy is crucial to success. The failure of a business or if it goes wrong is due not to the lack of the strategy or use to the wrong strategy, but to the work implementation by managers, particularly by the middle managers from the organization. So, if the implementation is not carefully planned, the strategic objectives may not be accomplished. The implementation is a rigorous process involving a series of logically connected activities that allow to an organization to adopt a strategy and to make it work. Developing such a logical approach is a challenge for management.

An efficient system should cover as many (if not all) activities related to the strategy execution and allow to management the pursuit in real-time (snapshot) all the indicators of business and the "smoke detector parties" that detours and dangers signals since the early stages.

Basically, a good part of the value of such a system, results from the metrics that it can give, a simple ones (values, graphs, etc.) and complex ones, compound and calculated with specific formulas (Business Intelligence).

\section{The information and asset's security}

You know that they stole from you as much as to move you form profit to loss. They blame the customers, the suppliers, the robbers, but some to others not. And you have doubled the guard, you put cameras and ordered financial or technological audit, but for nothing. Yes, your employees stealing you and if you don't want to go bankrupt have to catch them. The solution:

- The Business Intelligence application. Associated the schedules productivity and the cash flow with each employee. You see what happens when one is on leave, who stay overtime, etc. Find the possible causes of each inventory changes and narrows them until you have a name;

- Inquisition. Search your own freight market. Redeem it systematically and establish a tracking method to discover the pathway;

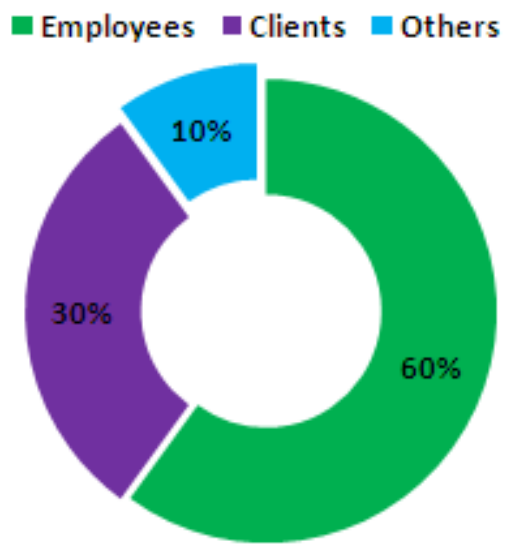

Romania

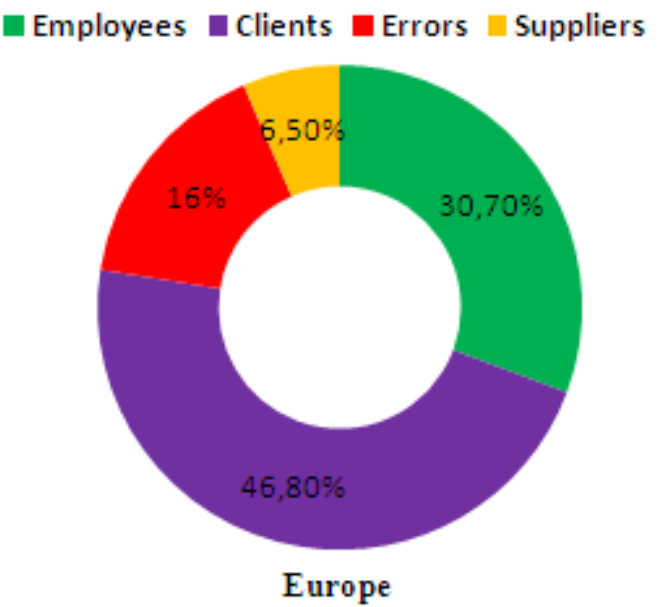

Europe

The distribution of losses in stores, as percentage, in Romania, namely in Europe, in 2008 
- Rotation of post. The thieves need to cover their tracks constantly. Move them from post and get on someone new, to learn what it is. Do not accept excuses like: only I can do that. Your interest is that more people to know what suppose a post;

- Audit surprise. Make unannounced inspections. In that way, the thieves will not have time to cover with bills or documents the holes that are in stock;

- Track-record. Check the history of employees outside the company. Call the former employers for references;

- Gratifications. Reward the castings and promise them confidentiality. Open an anonymously line by that you can receive information;

- Amnesty. Give them the chance to bring back what they stole, with the promise that nothing will happen with them, but that for the rest will be severe controls;

- Loan System. If you sell items for personal use or tools, let your employees to take home some models, on signature. That way reduces the temptation to steal objects that are stored only once;

- Screening. Check whether the employees meet income with their lifestyle. It may happen that their BMW be taken, however, from your money;

- Menace. No confidentiality. Where is found, give to the thief as much negative publicity.

A good Business Intelligence system has to make all the processes through is known that can be stolen as transparent as possible. The information must be maintained throughout the history of the company and it's good to have a strong system of "tracking" by which to trace who and what transaction ever made.

\section{The Mobile Office}

The mobile office...is talking about it for a while: to be able to work from home, from hotel, so you can move to the client for a week and work as if you were in your office, to sit to any computer and finish what you had to do- is not bad, especially when the crisis in the city, when the company reduced its space to save on rent, when bosses are thinking even to introduce shift work, when the distance from home to office or from a customer takes two hours...

\section{Stringency}

The more the company is bigger, the more people will hate you, more are frustrated and will consider themselves wronged; it doesn't matter here, whether is rightly or not. Some of them will leave the company at the earliest opportunity, others will be expelled, while others will remain in the company and will try to make themselves "justice". In any case, the manager can understand that he doesn't know about any project in what stage is, what is done and what to do in future; he will be surprised to find that some data files, contact lists or other such documents, that were there a few days ago, now aren't ...

Especially in Romania, the systems with "anti-frustration" architecture seem to be the most appropriate at this time. First, it's good to check that the system doesn't allow to an employee, no matter how angry he is, do irreparable damage, if he puts that in his mind. A software good enables to a new / another employee to sit at computer and, with the username and the password of the person disappeared to take any project exactly from the point that it was left and continue it without the others (especially customers) to realize.

\section{The right culture}

The organizations must develop cultures that support the implementation. For implementation is needed a culture for exploit the achievements, discipline and a sense of ownership.

But developing or changing a culture is not an easy task. Certain activities with the management team (so-called team-buildings), like climbing mountains, rafting on the water's swirl, paintball battles and others can be fun. It is essential for a successful implementation to 
know what really produces a cultural change. A Business Intelligence system is based upon such a structure.

From the various Business Intelligence systems is considered important to note the one of Jakobiak, proposing a model for Business Intelligence based on five main points ${ }^{11}$ :

1. A doctrine that give a definition for Business Intelligence recognized by the entire group;

2. An approach consist in:

a) an overall plan for moving from theory to method (the information flows from who come and for what purposes are proposed, which actors will act, the monitors, the analyzers, the policy makers etc..) in order to develop and implement a coherent strategy.

b) an overall plan to develop this method and to introduce structure, control cost and schedule problems.

3. A structure of two networks: poly network information (the selected areas of monitoring) and network analysis (expert groups and the selection of critical success factors).

4. An experiment which defines the rules for operating Business Intelligence within the organization: degree of freedom for each group, recommendations and guidelines, media and technical support (software, materials, etc.), data storage (types of information taken into account).

5. A quantitative and qualitative control.

The cornerstone for Jakobiak's model is the network of the experts in analysis- the raw information is sent to the observers, is transformed into developed information usable and interpreted by the decision factors.

The limits of the model derive from the separation of phase observation process, including analysis, and isolate the different actors involved, assuming a large number of intermediaries.

\section{Conclusion}

Finally, the decisions are more effective if the information about business and competitors are analyzed using Business Intelligence applications, providing opportunities for extrapolation and achieving accurate predictions on future economic trends and conditions. It provides to the companies and to users from all hierarchical levels a strong, complete and powerful technology, to extract from the large amount of existing data the key information relevant and useful for decision making and for the control of business.

The knowledge of all business aspects and understanding the factors with positive influence, especially those with a negative impact is a prerequisite for improving the company's performance and for rising on market. By using these technologies, the companies learn what happened in their business, why it happened and what will happen, all these added to the users experience and intuition, leading to obtaining competitive advantage. Meanwhile, Business Intelligence solutions help to eliminate the communication barriers within the company, help to the information security and enable the decisions based on consistent information and collaborative support.

11 Jakobiak, F. (2004), L'intelligence économique: la comprendre, l'implanter, l'utiliser, Ed. d’Organisation, Paris 


\section{References:}

1. Baets, W. R. J. (2005), Knowledge Management and Management Learning: Extending the Horizons of Knowledge- Based Management, Springer's Integrated Series in Information Systems, Vol. 9

2. Giovinazzo, W., A. (2002), Internet - Enabled Business Intelligence, Prentice Hall PTR

3. Jakobiak, F. (2004), L'intelligence économique: la comprendre, l'implanter, l'utiliser, Ed. d'Organisation, Paris

4. Lesca, H., Caron, M. L. (1995), Veille stratégique: créer une intelligence collective au sein de l'entreprise, Revue francaise de Gestion, 105, pp. 58-68

5. Lesca, H., Sadok M. (2009), A Business Intelligence Model for SMEs Based on Tacit Knowledge, Communications of the IBIMA, volume 7, ISSN: 1943-7765

6. Moss, L. T., Atre, S. (2003), Business Intelligence Roadmap: The Complete Project Lifecycle for Decision-Support Applications, Ed. Addison Wesley

7. Muntean, M. (2004), Inițiere în tehnologia OLAP. Teorie şi practică, Ed. ASE, Bucharest

8. Power, D. J. (2007), A Brief History of Decision Support Systems, available on-line at http://dssresources.com/history/dsshistory.html

9. Salles, M. (2003), Stratégies des PME et intelligence économique: une method d'analyse du besoin, Ed. Economica, Paris

10. Shaw, T. (2004), Shaku Atre Interview: What is Business Intelligence?, available on-line at www.dssresources.com

11. Velicanu, M., Matei, G. (2007), Databases versus Data Warehouses, Communication at the 8th edition of the Conference of Economic Informatics, Ed. ASE Bucharest, published in the Conference volume 